\title{
Debris flow hazard mapping with a random walk model in Korea
}

\author{
H.-J. Youn, C.-W. Lee \& C.-S. Woo \\ Korea Forest Research Institute, Korea
}

\begin{abstract}
Recently, the sediment-related disasters, including landslides and debris flows, have been getting bigger due to the increasing intensity of typhoons and downpours that are affected by climate change. In particular, the debris flow is a severe disaster because it brings serious damage to villages and agricultural fields, as well as casualties. In order to reduce the damage caused by debris flows, this study carried out the predicting simulation of the affected area using a random walk model. The data of 12 debris flows were extracted from aerial photos taken in Inje and Pyeongchang counties, Gangwon province and Bongwha county, Gyeongbuk province, Korea in 2006 and 2008. In order to identify optimum parameter sets of the random walk model, these data of debris flows were used. There are three parameters, which are soil volume at a time, stop angle and inertia weight. These parameters are optimized when showing the highest correspondence rate, which means there is a comparison between a simulated sediment area and an actual sediment area after simulating 1,250 of combinations. The simulation was conducted to extract the optimum parameters, and the method of calculating the correspondence rate was developed to evaluate the value of parameters. The criteria for determining the danger and warning zone and the soil volume of collapse were prepared to make the debris flow hazard map. The debris flow hazard maps in Inje and Pyeongchang counties of Gangwon province and Bongwha county of Gyeongbuk province were made on the scale of 1:5,000. The hazard map will be helpful in deciding danger-prone zones and sites for soil erosion control works.
\end{abstract}

Keywords: landslide, soil volume at a time, stop angle and inertia weight, correspondence rate. 


\section{Introduction}

It is important to predict dangerous torrents, flowing paths and deposit zones to reduce the damage of debris flow $[1,2,4]$. Developed countries, such as Japan, Austria and the United States, developed the technique of predicting hazard zones and applied them to their land $[5,8,9,11]$. In particular, according to the Geographic Information System (GIS), the study of hazard mapping using potential soil erosion ability and the patterns of erosion and deposit was conducted actively. The technique of hazard mapping is divided into two parts, which are developing the model for prediction and hazard mapping. The models include an answer model and a physical model. The answer model uses a statistical method based on experiences [3] and the physical model uses the numerical study after using a complicated physical equation to simplify it [5-7, 10]. Hazard mapping is the techniques of deciding dangerous areas and zoning the territory of those areas predicted through the model, damage record and sensitivity. In this study an answer model was applied and the hazard map was drawn using the occurrence data of debris flows in order to reduce the damage by debris flow.

\section{Methods and materials}

\subsection{Identifying the optimum parameters}

Figure 1 shows the procedure for identifying the optimum parameters. After extracting the occurrence source and deposit area from the aerial photos of debris flow, the range of parameters was decided. The parameter sets were applied to the Random Walk Model (RWM) (Imamura et al, 1980) and the correspondence rate was calculated repeatedly. Those showing the highest correspondence rate were chosen as the optimum parameters.

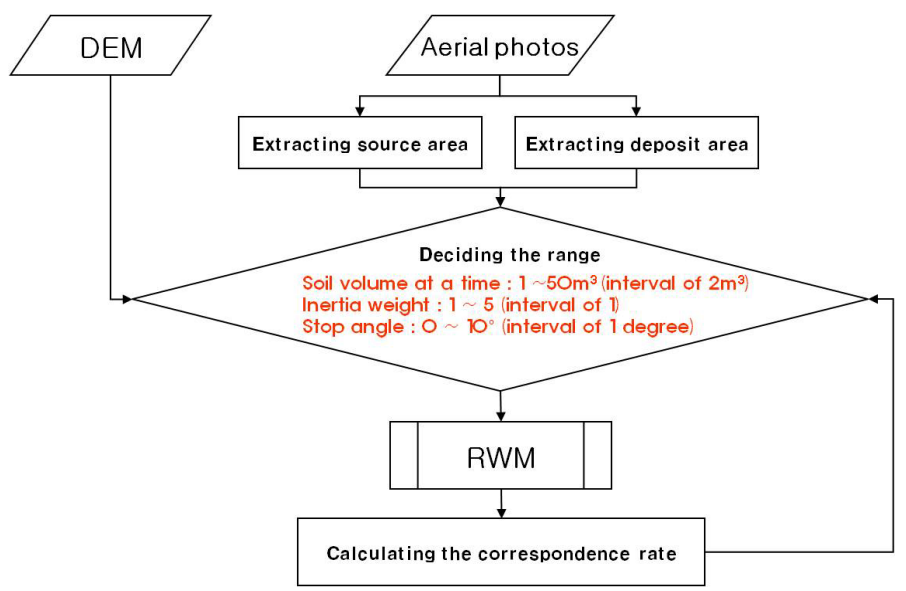

Figure 1: The procedure for identifying the optimum parameters. 


\subsubsection{Simulation for deciding optimum parameter sets}

When the deposit model is applied, the optimum parameter sets representing each local area have to be decided. The object areas are Inje and Pyeongchang counties in Gangwon province and Bongwha county in Gyeongbuk province. The three parameters are soil volume at a time, inertia weight and stop angle. The ranges of these three parameters were decided individually. The range of soil volume at a time was decided from 1 to $50 \mathrm{~m}^{3}$, that of inertia from 1 to 5 , and that of stop range from 0 to 10 degrees individually. Four sample areas for each county were selected and in total 12 spots were chosen. The set of 1,250 parameters was applied to each sample area. The selection of the sample area was made, based on the minimum influence by the outside and the clear shape of deposit. The total soil volume was estimated by multiplying the area of the occurrence source and the average soil depth.

\subsubsection{Correspondence rate}

The correspondence rate was developed to find how much two areas of hazard zone predicted from RWM and actual deposit zones extracted by aerial photos are similar each other. Figure 2 shows the method to calculate the correspondence rate. The results are from -1 to 1 . The correspondence rate of -1 means that the estimated zone does not completely correspond with the real deposit zone and 1 means that the estimated zone completely corresponds with the actual deposit zone completely. A rate of 0 means that the correspondence is $50 \%$, in other words, the estimated zone corresponds with half of the actual zone.

Figure 3 shows the schematic diagram of the results for the correspondence rate. If the estimated deposit zone is concentrated on almost one point, the correspondence rate might show 0 . However, this is very unlikely. There is need to develop the method of representing the extent of spread in the near future.
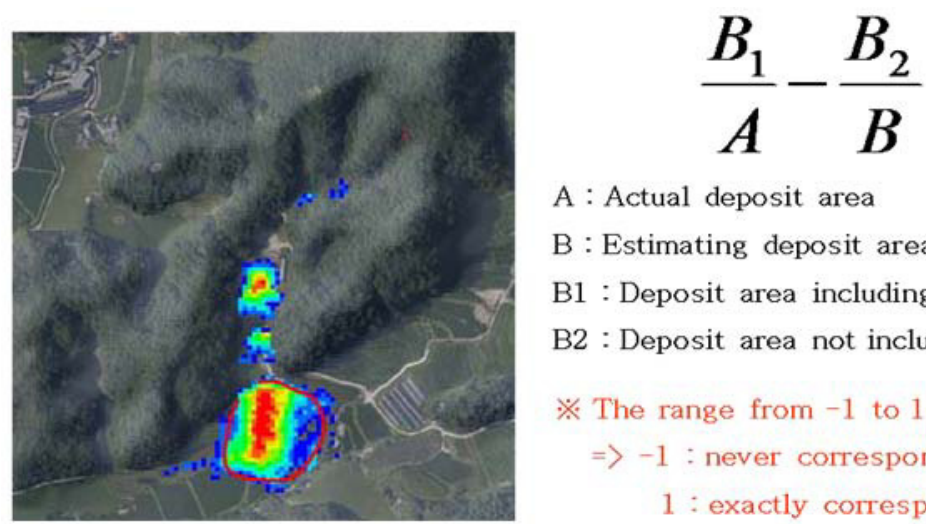

A : Actual deposit area

B : Estimating deposit area (B1+ B2)

B1 : Deposit area including A

B2 : Deposit area not including A

The range from -1 to 1

$\Rightarrow-1$ : never correspond

1 : exactly correspond

Figure 2: The method to calculate the correspondence rate. 


\section{Correspondence rate}

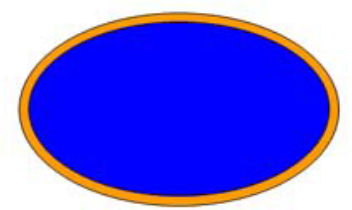

Close to value 1

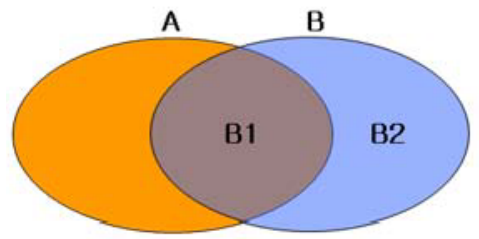

Close to value 0
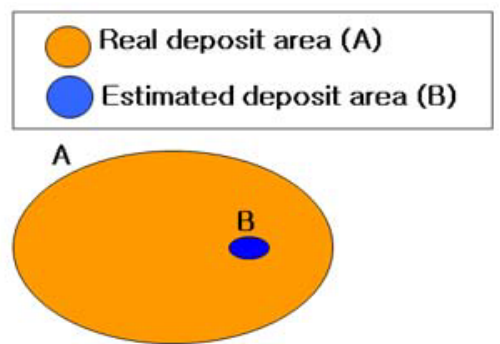

Close to value 0

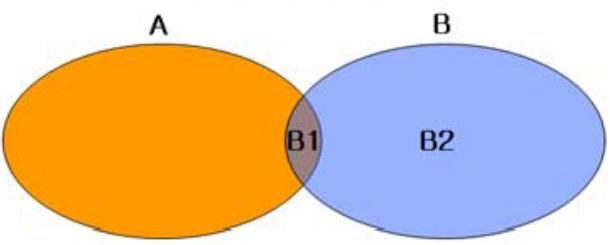

Close to value -1

Figure 3: The schematic diagram of the results of the correspondence rate.

\subsection{Making the debris flow hazard maps}

As well as the parameter sets, the total soil volume of collapse needs to be estimated. So those of the danger and warning zones were calculated individually. In calculating the soil volume of collapse, the area of most danger rating in the landslide hazard map and the areas of landslide occurrence from years 2000 to 2008 were used. Hazard mapping was drawn using RWM and the danger and warning zones were divided by applied soil volume of collapse.

\subsubsection{Calculating the soil volume of collapse in the danger zone}

The soil volume of collapse of the danger zone was assessed on the assumption that the 1st grade area in the landslide hazard map was collapsed totally. So the soil volume of collapse is decided by the 1st grade area multiplied by the average soil depth in the digitalized forest soil map. However, a danger zone exists in case that there is no 1st grade area. The estimated zone of RWM was decided by applying this soil volume of collapse.

\subsubsection{Calculating the soil volume of collapse in the warning zone}

The soil volume of collapse of the warning zone was estimated from the data of the existing landslide occurrence. After calculating the ratio of landslide area in other grades, except the 1st grade, from the existing landslide data from years 2000 to 2008, the collapse area was calculated by multiplying the object area by this ratio. The soil volume of collapse was estimated by multiplying the collapsed area by the average soil depth in the digitalized forest soil map. To secure a wider area of the safe zone, the final area of the warning zone was calculated by applying the multiple of the difference between the maximum landslide area and the average. This consideration is to secure more areas in the 
warning zone as a safe zone as landslides have increased recently because of unusual rainfall. The estimated zone of RWM was determined by applying this soil volume of collapse.

\section{Making the debris flow hazard maps}

\subsection{Identifying the optimum parameters}

\subsubsection{Simulation for deciding on optimum parameter sets}

The parameters sets of soil volume at a time, inertia weight and stop angle are determined for the case that the correspondence rate showed the highest value. Figure 4 shows the results of the sensitivity analysis between parameters in the case of Bongwha county in Gyeongbuk province. The figure shows the correspondence rate $(\mathrm{Z})$ on a combination of two parameters sets $(\mathrm{X}, \mathrm{Y})$. The first figure shows the sample area in aerial photos, the second figure shows the correspondence in the case of the soil volume at a time of horizontal axis and the stop angle of the vertical axis. The third figure shows the relation of the soil volume at a time to the inertia weight. The fourth figure shows the relation of the soil volume at a time to the stop angle. The soil volume at a time and the stop angle showed a high correspondence rate in a certain range. It is evident that those two parameters have high influence on the results of RWM. However, the inertia weight is not sensitive to different ranges. So this parameter has little influence on the results in all object areas.
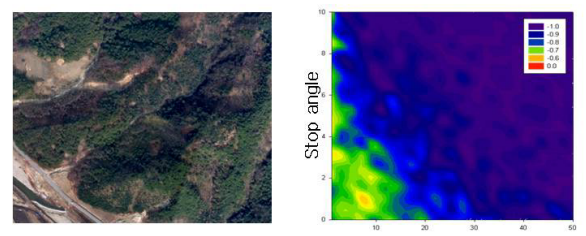

Soil volume at a time
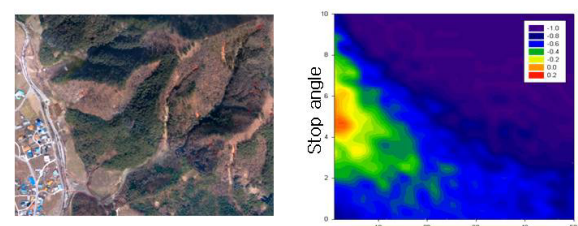

Soil volume at a time

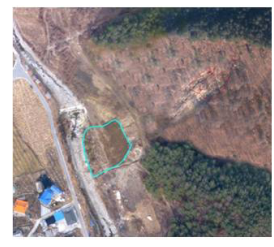

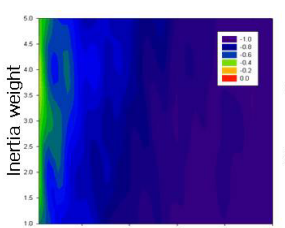

Soil volume at a time

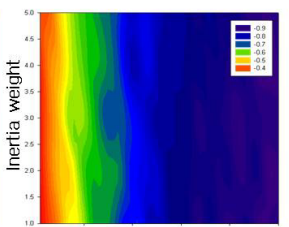

Soil volume at a time

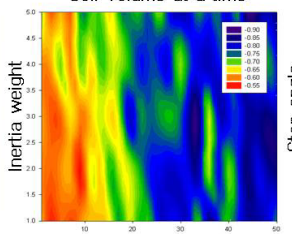

Soil volume at a time

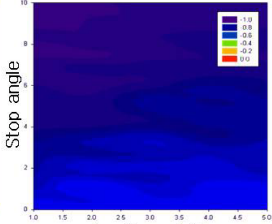

Inertia weight

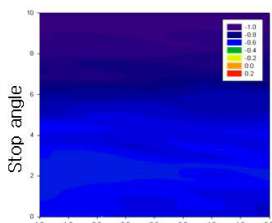

Inertia weight

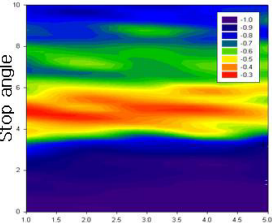

Inertia weight

Figure 4: The results of sensitivity analysis between parameters in Bongwha county. 


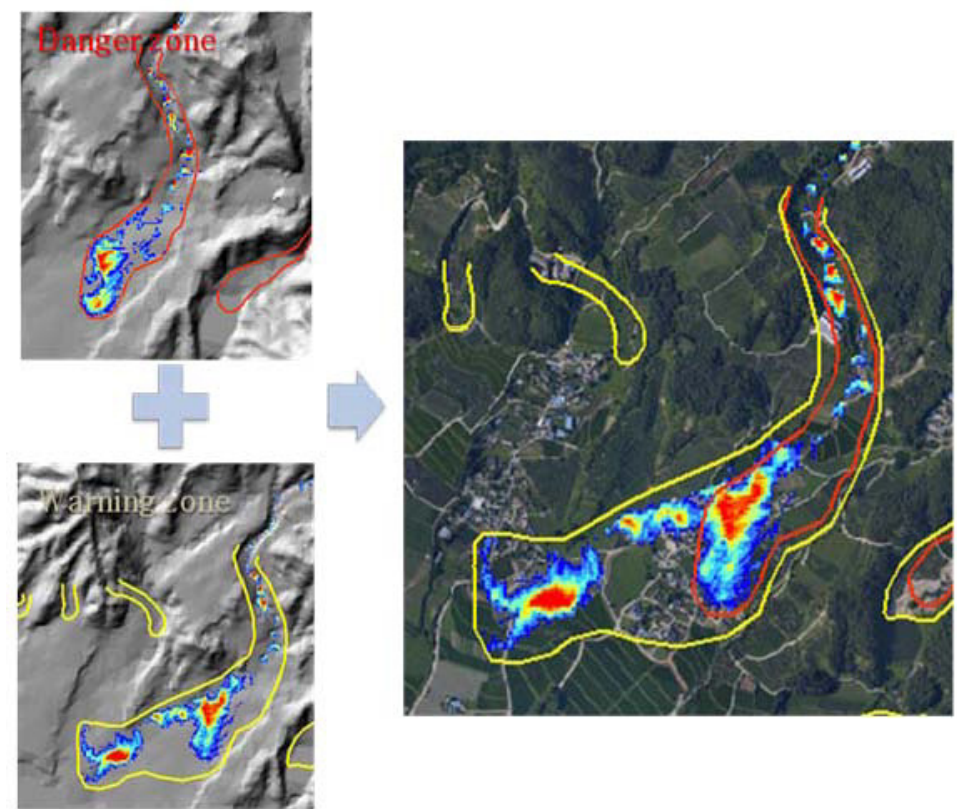

Figure 5: Determining the optimum parameters in Bongwha county.

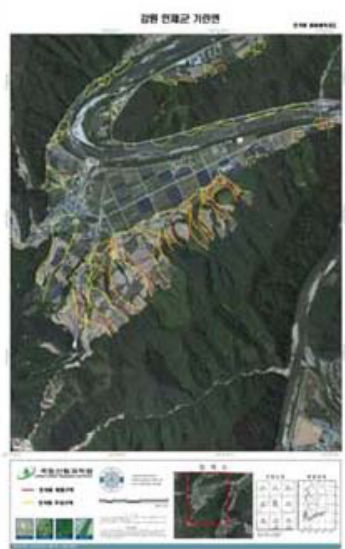

〈Inje county, Gangwon province〉

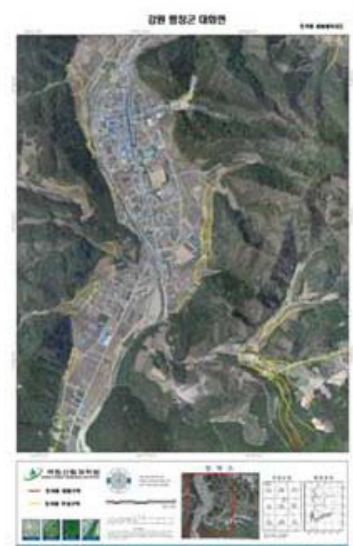

〈Pyeongchang county, Gangwon province〉

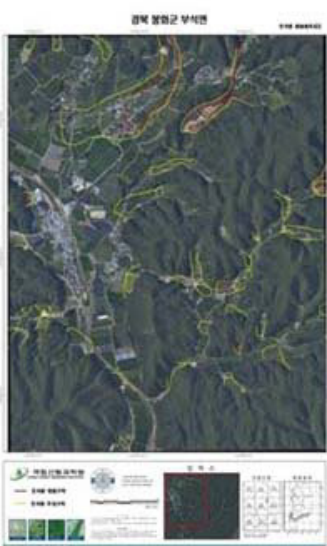

〈Bongwha county, Gyeongbuk province〉

Figure 6: The optimum parameters in Inje, Pyeongchang and Bongwha counties.

\subsubsection{Identifying the optimum parameters}

The correspondence rate is averaged by the overlapping approach of soil volume at a time and stop angle of four sample areas in Bongwha county in Gyeongbuk province (Figure 5). When the correspondence rate between the soil volume at a 


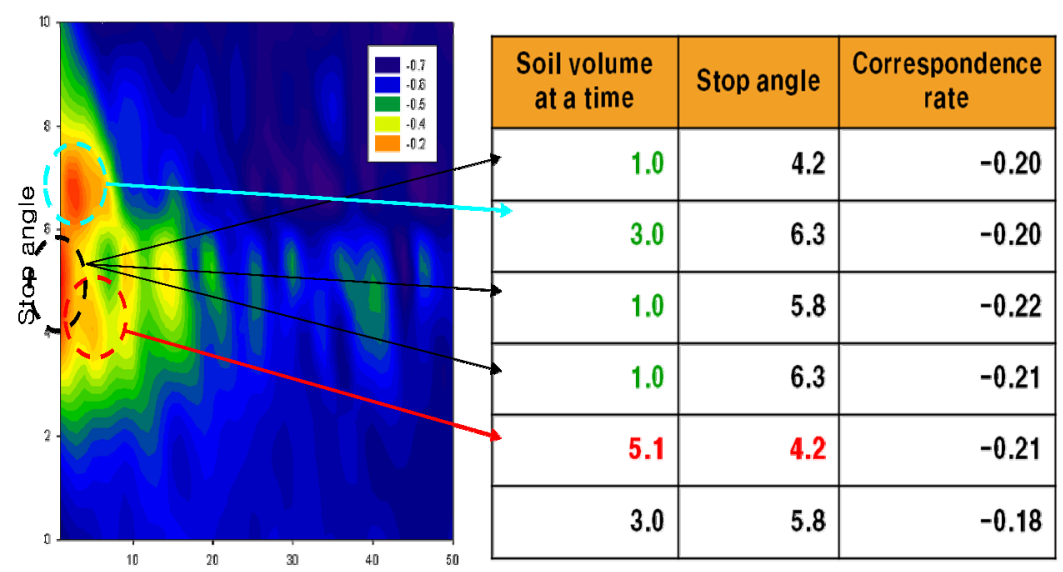

Soil volume at a time

Figure 7: $\quad$ The procedure of making a debris flow hazard map (colour online only).

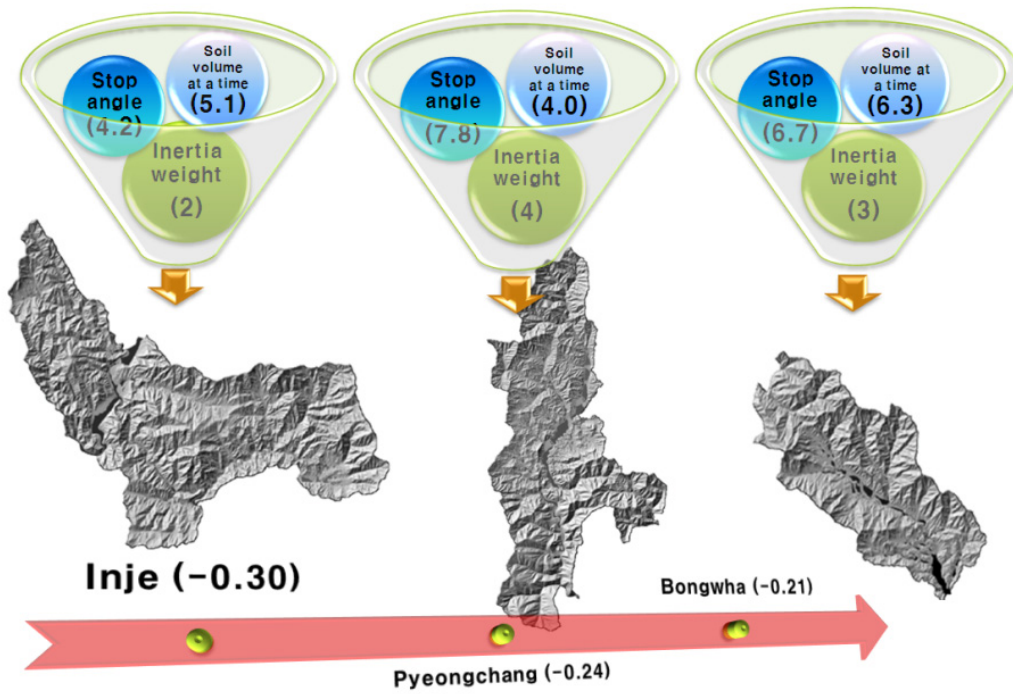

Figure 8: The debris flow hazard maps in object areas on the scale of 1:5,000.

time and stop angle showed the highest, the inertia weight showed that the highest correspondence rate was applied. The optimum value of the soil volume at a time was $1.0 \mathrm{~m}^{3}$, the stop angle was 4.2 degrees, and the inertia weight was 2 . In this case the correspondence rate average was -0.24 . However, in the case of the soil volume at a time under $3.0 \mathrm{~m}^{3}$, the results of RWM was excepted 
because that calculation was not possible. Finally, the optimum value of the soil volume at a time was $5.1 \mathrm{~m}^{3}$, the stop angle was 4.2 degrees, and the inertia weight was 2 . In this case the correspondence rate average was -0.34 . The reason for the correspondence rate mostly showing the value under zero is that the soil volume of the bottom and sides of the torrent area are not included all together. A resolution to this problem has to be developed in the near future. The optimum parameters of Inje and Pyeongchang counties were decided by the same method as figure 6.

\subsection{Making the debris flow hazard map}

According to the RWM applying optimum three parameters, the debris flow hazard maps were made. The soil volume of collapse was calculated by the danger and warning zones individually. The danger zone was coloured in red and the warning zone in yellow in figure 7 . Figure 8 shows the debris flow hazard maps in object areas on the scale of 1:5,000.

\section{Conclusions}

\subsection{Identifying the optimum parameters}

The simulation was conducted to extract the optimum parameters, and the method of calculating the correspondence rate was developed to evaluate the value of parameters. According to the correspondence rate and distribution range, the parameters were decided by object areas. The optimum value of the soil volume at a time was $6.3 \mathrm{~m}^{3}$, the stop angle was 6.7 degrees and inertia weight was 3 in Inje county. In Pyeongchang county the optimum value of the soil volume at a time was $4.0 \mathrm{~m}^{3}$, the stop angle was 7.8 degrees and inertia weight was 4 . The optimum value of the soil volume at a time was $5.1 \mathrm{~m}^{3}$, the stop angle was 4.2 degrees and the inertia weight was 2 in Bongwha county.

\subsection{Making the debris flow hazard map}

The criteria of determining the danger and warning zone and the soil volume of collapse were prepared to make the debris flow hazard map. The debris flow hazard maps for Inje and Pyeongchang counties in Gangwon province and Bongwha county in Gyeongbuk province were made on the scale of 1:5,000.

\section{References}

[1] Korea Forest Research Institute. 2002. The causes and rehabilitation measures of sediment disaster. 317pp.

[2] Chun, K. Kim, M, Park, W. and Ezaki, T. Characteristics of channel bed and woody debris on mountainous stream. 1997. Jour. Korean For. Soc. 86(1): 69-79. 
[3] Imamura, Y. and Sugita, M. 1980. Study on the simulation of debris flow depositing based on Random Walk Model. Japan Society of Erosion Control Engineering. 114: 17-29.

[4] Satofuka, Y. and Mizuyama, T. 2005. Numerical simulation on a debris flow in a mountainous river with a Sabo dam. Japan Society of Erosion Control Engineering. 58(1): 14-19.

[5] Miyamoto, M. 2002. Two dimension numerical simulation of landslide mass movement. Society of Erosion Control Engineering. 55(2): 5-13.

[6] Suzuki, T., Hotta, N. and Miyamoto, K. 2003. Influence of riverbed roughness on debris flows. Japan Society of Erosion Control Engineering. 56(2): 5-13.

[7] Hirakawa, Y., Suwa, H, Fukuda, K and Kobayashi, N. 2006. Application of PIV method for the measurement of surface velocity of debris flow. Japan Society of Erosion Control Engineering. 59(2) : 49-54.

[8] Hechmann, T., Wichmann, V. and M. Becht. 2002. Quantifying sediment transport by avalanches in the Bavarian Alps-first results. In: Zeitschrift fur Geomorphologie N. G., Suppl.-Bd. 127:137-152.

[9] Hotta N. and Ohta. T. 2000. Pore-water pressure of debris flows. Physics and Chemistry of the Earth (B), Vol.25, No.4: 381-386.

[10] Pirulli, M. and Sorbino, G. 2008. Assessing potential debris flow runout: a comparison of two simulation models. Nat. Hazards Earth Syst. Sci., 8, 961-971.

[11] Takahashi, T. 2007. Debris Flow Mechanics, Prediction and Countermeasures. Taylor \&Francis. 5-7. 